\title{
Stuck in the mud? Earthquake nucleation and propagation through accretionary forearcs
}

\author{
D. R. Faulkner, ${ }^{1}$ T. M. Mitchell, ${ }^{2}$ J. Behnsen, ${ }^{1}$ T. Hirose, ${ }^{3}$ and T. Shimamoto ${ }^{4}$ \\ Received 17 June 2011; revised 24 August 2011; accepted 24 August 2011; published 20 September 2011.
}

[1] Subduction zone earthquakes can propagate to the surface causing large seafloor displacements resulting in tsunamis. This requires the earthquake to rupture through clay-rich sediments of the accretionary wedge, which are largely aseismic. As found previously, the frictional properties of a range of wet clays at low slip velocity are velocity strengthening, thus inhibiting earthquake nucleation. However, at high slip velocity the same materials weaken almost immediately resulting in a negligible critical slip weakening distance and fracture energy. We interpret this behaviour as rapid thermal pressurization of the pore fluid within the clay gouge. The lack of fracture energy can explain how a large rupture, propagating from depth, might not be arrested by clay-rich, velocity-strengthening sediments, as is commonly seen. The results suggest that generally, earthquakes may be difficult to nucleate on mature faults dominated by clay, but the propagation of earthquakes through these zones is energetically very favourable. Citation: Faulkner, D. R., T. M. Mitchell, J. Behnsen, T. Hirose, and T. Shimamoto (2011), Stuck in the mud? Earthquake nucleation and propagation through accretionary forearcs, Geophys. Res. Lett., 38, L18303, doi:10.1029/ $2011 \mathrm{GL} 048552$.

\section{Introduction}

[2] Subduction zone earthquakes can be accompanied by significant seabed uplift resulting in devastating tsunamis. A graphic example is the recent M9.0 Tohoku-Oki earthquake in 2011 that produced $\sim 30$ m of slip at the trench [Ide et al., 2011]. One common feature of subduction zones is that within $\sim 50 \mathrm{~km}$ arc-ward of the trench there is a distinct lack of recorded seismicity [Hyndman et al., 1997; Oleskevich et al., 1999; Haberland et al., 2009] (Figure 1). This up-dip limit of seismicity ranges in depth from 5 to $15 \mathrm{~km}$. The lack of seismicity above these depths has been attributed to the velocity strengthening and hence stable sliding frictional properties of clay-rich sediments contained within the accretionary wedge [e.g., Saffer and Marone, 2003]. The frictional properties of clays have been well studied [Logan and Rauenzahn, 1987; Saffer and Marone, 2003; Moore and Lockner, 2004; Ikari et al., 2009] at slow slip velocities

\footnotetext{
${ }^{1}$ Rock Deformation Laboratory, Department of Earth and Ocean Sciences, University of Liverpool, Liverpool, UK.

${ }^{2}$ Experimental Geophysics Laboratory, Institute for Geology, Mineralogy, and Geophysics, Ruhr-University Bochum, Bochum, Germany.

${ }^{3}$ Kochi Institute for Core Sample Research, JAMSTEC, Nankoku, Japan.

${ }^{4}$ State Key Laboratory of Earthquake Dynamics, Institute of Geology, Chinese Earthquake Administration, Beijing, China.

Copyright 2011 by the American Geophysical Union. 0094-8276/11/2011GL048552
}

$(<1 \mathrm{~mm} / \mathrm{s})$. However, although this velocity-strengthening behaviour can explain the lack of earthquake nucleation in this zone, it does not explain why subduction megathrust earthquakes are able to propagate easily to the surface throughout this zone.

[3] Often earthquakes propagating through the accretionary wedge have unusual properties. These include low rupture propagation (sometimes under half the Rayleigh wave speed), and the amount of slip is actually much larger than expected from the recorded surface wave magnitudes [Kanamori, 1972]. This can lead to problems with shortterm prediction of tsunamis from seismic measurements. This feature can be partly explained by the low rigidity of the sediments in the forearc accretionary wedge [Geist and Bilek, 2001], as seismic moment calculations assume rock rigidity. Similarly, a greater surface offset can be produced if the rupture event splays off the main detachment onto a steeper fault near the surface [Wendt et al., 2009]. Finally, a large surface offset can be produced if dynamic overshoot from extreme weakening of the fault in the accretionary wedge occurs, as is suggested for the Tohoku-Oki earthquake, where an abundance of normal fault aftershocks near the trench were recorded [Ide et al., 2011].

[4] Explanations for why large ruptures appear to propagate through the shallow aseismic region has included frictional conditional stability of the forearc sediments, where the clay-rich sediments can sometimes inhibit earthquake nucleation (velocity strengthening) and sometimes allow earthquakes (velocity weakening), with an overall neutral frictional stability [Bilek and Lay, 2002]. However, the vast majority of clays show velocity strengthening behaviour [Logan and Rauenzahn, 1987; Saffer and Marone, 2003; Moore and Lockner, 2004; Ikari et al., 2009] and mixtures of clay and quartz still show the same characteristics, even when the clay fraction is small [Crawford et al., 2008; Tembe et al., 2010]. Some smectite clays exhibit complex and frictionallyunstable behaviour at low normal stresses [Saffer et al., 2001], but it is uncertain if the concentration of smectite clays in accretionary prisms is sufficient to allow neutral frictional stability. Also high pore-fluid pressures have been invoked as a mechanism for reducing frictional stability in the forearc region [Seno, 2002].

[5] We investigate the notion that the frictional properties of clay-rich materials vary as a function of slip velocity, and that earthquake propagation may not necessarily be inferred from the slow-slip velocity-strengthening behaviour (rate and state friction behaviour).

\section{Methods}

[6] We measured the frictional properties of five samples of clay-rich material at low (between $0.5 \mu \mathrm{m} / \mathrm{s}$ and $5 \mu \mathrm{m} / \mathrm{s}$ ) 


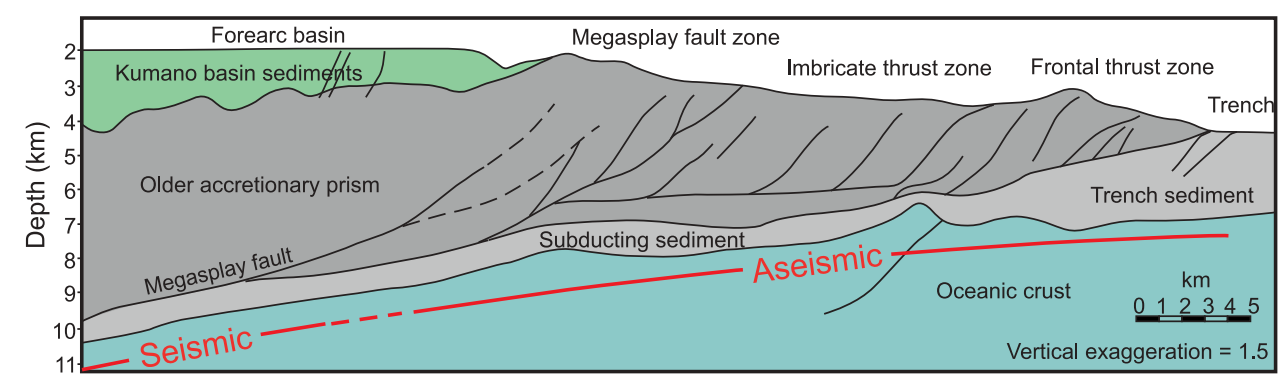

Figure 1. A typical cross section through a subduction zone (based on the Nankai trough [Tobin et al., 2009]), illustrating the gap in seismicity recorded arc-ward from the trench.

and high slip velocities $(1.3 \mathrm{~m} / \mathrm{s})$ under initially dry and saturated conditions. In these samples, the dominant clays were illite, montmorillonite, pyrophyllite, sericite and talc (see Table 1). In the case of montmorillonite, talc and sericite, the proportion of clays was greater than $75 \%$. The illite sample contained $45 \%$ illite, with quartz and calcite the other major components. The pyrophyllite contained muscovite and kaolinite and around 30\% quartz. All mineralogical analyses were determined using XRD with Rietveld refinement.

[7] The low slip-velocity experiments were conducted on a conventional triaxial deformation apparatus with servocontrolled pore and confining pressure systems [Mitchell and Faulkner, 2008] under effective normal stresses of $10 \mathrm{MPa}$ at 0.1 to $1 \mu \mathrm{m} / \mathrm{s}$ slip velocity. The load was measured with an internal force gauge. Powders of the clay-rich material were placed in a porous stainless steel cylinder precut at an angle of $30^{\circ}$ to the axis with an initial thickness of $1 \mathrm{~mm}$. They were jacketed in $2 \mathrm{~mm}$ thick PVC sleeve, and a Teflon shim was used to decouple the sawcut sliders from the loading piston [Smith and Faulkner, 2010]. The samples were pressurized to $10 \mathrm{MPa}$ confining pressure, and the pore fluid connections were left open to laboratory conditions during the first dry stage of sliding. The normal stress was maintained at $10 \mathrm{MPa}$ across the sawcut by controlling the confining pressure as load was increased. After dry sliding, the sample was flooded with de-ionized water at $10 \mathrm{MPa}$ and the confining pressure increased to $20 \mathrm{MPa}$.

[8] The high slip-velocity experiments were conducted in a high-velocity rotary shear apparatus at $1.63 \mathrm{MPa}$ normal stress and slip velocity of $1.3 \mathrm{~m} / \mathrm{s}$ [Shimamoto and Tsutsumi, 1994]. The low normal stress conditions in the experiments are appropriate to those found in the uppermost reaches of accretionary prisms. Extrapolation with further data would be needed to apply results to greater depth. The dry samples were prepared by placing $1 \mathrm{~g}$ of powder between the forcing blocks (gabbro or sandstone) and this powder was contained by a Teflon sleeve made to fit tightly around the sliders [Mizoguchi et al., 2007]. The shear resistance of the Teflon sleeve when the rotating blocks were not in contact in a control test is indicated in Figure 2b. The contribution of the friction of the Teflon sleeve is almost always lower than that of the gouge, and is therefore discounted. The normal stress was applied and maintained at $1.63 \mathrm{MPa}$. The equivalent slip velocity [Shimamoto and Tsutsumi, 1994; Han et al., 2007] was $1.3 \mathrm{~m} / \mathrm{s}$ in all experiments. For the wet tests, $0.5 \mathrm{ml}$ of de-ionized water was added to the gouge before sliding commenced.

\section{Results}

[9] In the low-velocity experiments, the clays were tested under atmospheric humidity ('dry' conditions) and then were flooded with de-ionized water and sheared again. The results are shown in Figure 2. The low slip-velocity results show that all the materials tested have high coefficients of friction at the low effective normal stress under which the experiments were performed, in agreement with previous work on clay-rich material under low effective normal stress [Saffer and Marone, 2003]. Montmorillonite may seem as though it has a relatively high friction coefficient, but the material used (Table 1) contains $\sim 23 \%$ quartz and feldspar, and this would be expected to raise the friction coefficient [Crawford et al., 2008, Figures 6 and 7]. The friction coefficient decreases upon the addition of water. Lower coefficients of friction develop in these materials under higher effective normal stress, particularly in the presence of water [Saffer and Marone, 2003; Moore and Lockner, 2004]. In the experiments, a velocity step was imposed to qualitatively determine whether the clays were velocity strengthening or velocity weakening under the test conditions. In all cases, the clays displayed velocity-strengthening behaviour (Figure 2), although in some this velocity dependence is weak.

[10] In the same way as the low velocity tests, in the highvelocity tests the materials were performed under atmospheric ('dry') conditions and also water saturated. There are few laboratory data on clay-rich material at higher slip velocities, such as those found in earthquakes $(\sim 1 \mathrm{~m} / \mathrm{s})$ and

Table 1. Details of the Experimental Material Used

\begin{tabular}{lccc}
\hline \multicolumn{1}{c}{ Mineral } & Purity & Other Components & Supplier and Source \\
Illite & $44 \%$ & Quartz 31\%, calcite 24\%, chlorite 1\% $\%$ Peach Pig Illite clay, Japan \\
Pyrophyllite & $49 \%$ & Quartz 32\%, kaolinite 14\%, muscovite 5\% & Nakarai Chemicals, Japan \\
Montmorillonite & $77 \%$ & Quartz 15\%, albite $8 \%$ & Na-bentonite, Yamagata Prefecture, Japan \\
Sericite & $85 \%$ & Calcite 13\%, chlorite 2\% & JCSS-5101, Japan \\
Talc & $88 \%$ & Chlorite $9 \%$, quartz 2\%, dolomite 1\% & J.T. Baker, USA \\
\hline
\end{tabular}



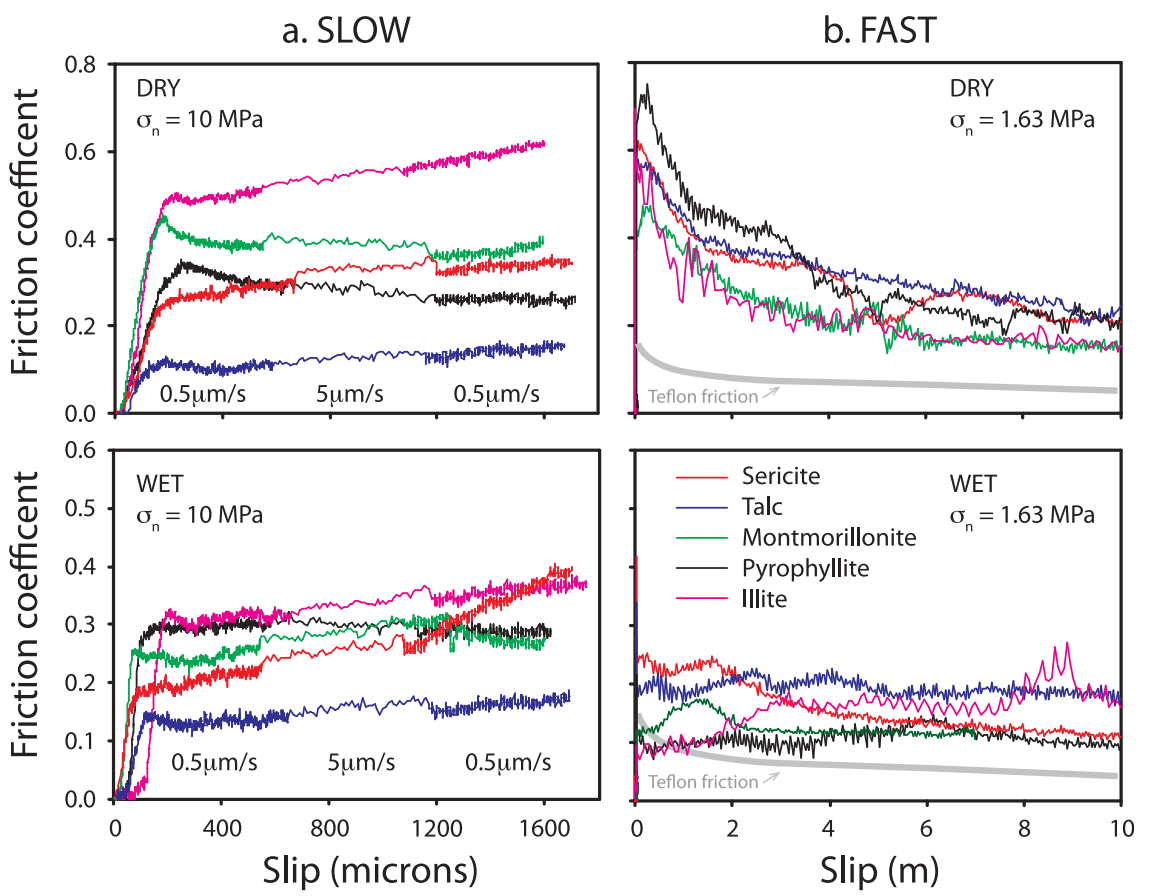

Figure 2. (a) Frictional properties of clays at low slip velocity $(0.5 \mathrm{~mm} / \mathrm{s}$ and $5 \mathrm{~mm} / \mathrm{s})$, wet and dry, and (b) frictional properties of clays at high slip velocity $(1.3 \mathrm{~m} / \mathrm{s})$, wet and dry.

those that exist have quite a low proportion of clay material, or were not tested under initially saturated conditions [Boutareaud et al., 2008; Brantut et al., 2008]. The dry tests show frictional behaviour that has been recognized in many other studies of fault gouge materials at high slip velocity. This is characterized by a peak in the friction coefficient after slip commences, followed by a prolonged weakening of the gouge over a slip weakening distance whereupon a steady state friction coefficient is reached [Brantut et al., 2008; Di Toro et al., 2011] (Figure 2).

[11] However, the key focus here is the behaviour of the gouges when saturated with water. All gouge materials displayed similar behaviour when wet and this was characterized by a loss of the peak friction seen in the dry tests and the almost immediate establishment of steady-state frictional sliding at very low friction coefficients. It is possible that the peak friction is still present but, given the sampling rates employed, we do not record it. Very similar behaviour was seen with natural gouge recovered from the accretionary wedge of the Nankai trough [Ujiie and Tsutsumi, 2010]. This type of behaviour, with extreme weakening and loss of peak friction, would not be predicted using regular rate and state formulations and would require additional rate-dependent physical weakening processes to be considered [Bizzarri and Cocco, 2006; Noda, 2008]. These observations clearly have important implications for earthquake rupture propagation.

\section{Discussion}

[12] The weakening of the gouge at high slip velocity is dramatic and has been attributed in other studies to flash heating at asperity contacts [Bowden and Tabor, 1950], thermal pressurization [Hirose and Bystricky, 2007; De
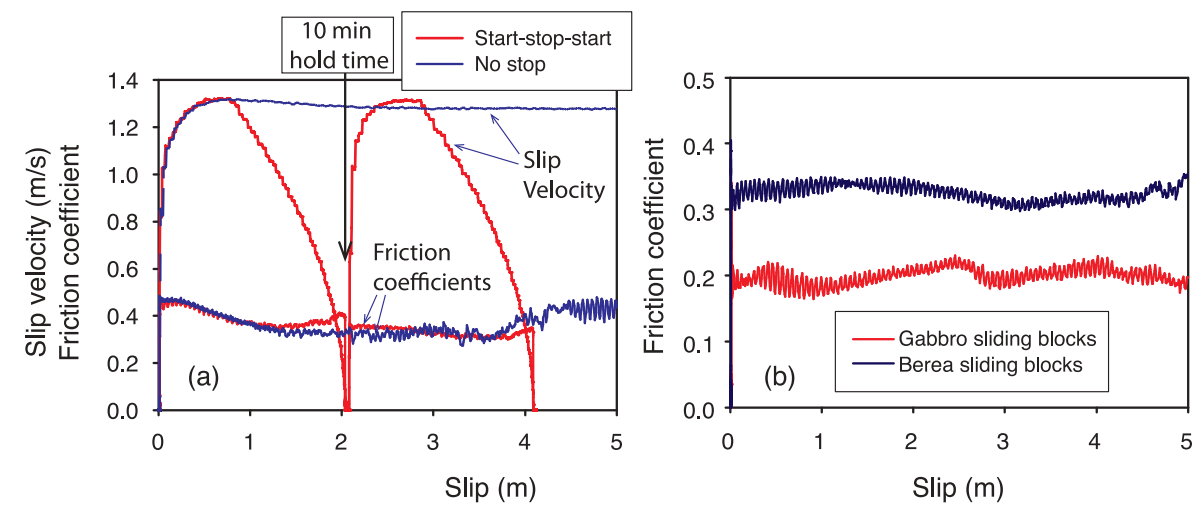

Figure 3. Tests devised to identify the mechanism by which the fracture energy is reduced in the wet experiments at high slip velocity (a) start-stop tests where the sample was spun at $1.3 \mathrm{~m} / \mathrm{s}$, stopped, then started again after a 10 minute hold period (b) showing the wet frictional behaviour while using permeable (Berea sandstone) and impermeable (gabbro) sliders. 

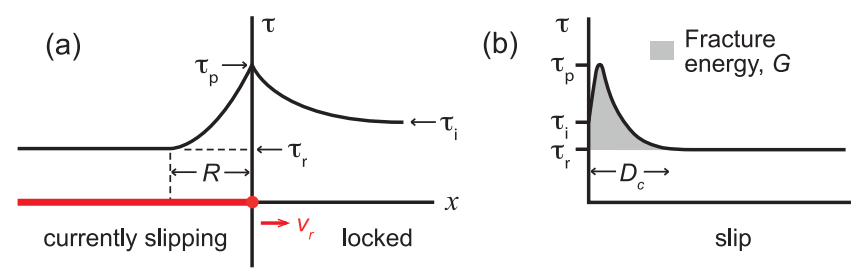

Figure 4. The stress distribution during an earthquake. (a) Schematic showing how stress varies around a propagating rupture, where $\tau_{\mathrm{i}}$ is the initial stress, $\tau_{\mathrm{p}}$ the peak stress and $\tau_{\mathrm{r}}$ is the residual stress. $\mathrm{V}_{\mathrm{r}}$ is the rupture velocity and $\mathrm{R}$ is the frictional breakdown distance. (b) The evolution of stress with slip at a point on the rupture surface; the area under the curve from the initial stress, to peak stress, to residual stress is termed the fracture energy of the earthquake and dictates the ease with which the rupture will propagate.

Paola et al., 2011], frictional melt lubrication [Di Toro et al., 2006], silica gel formation [Goldsby and Tullis, 2002] and thermal decomposition [Han et al., 2007]. In our experiments, the primary weakening mechanism for the dry experiments is inferred as flash heating of asperity contacts and thermal decomposition with associated thermal pressurization (shown by XRD evidence for decompositional products in post-experimental analyses).

[13] For the wet, high-velocity results, we devised experiments to identify the processes responsible for their weak behaviour. The process by which the loss of peak friction and weakening occurs is important to understand if the experimental results are to be extrapolated to nature. We hypothesized that these processes were (a) almost immediate thermal pressurization (b) pore pressure excess produced by mechanical compaction of the gouge during early shearing or (c) some type of physicochemical interaction of the pore water with the mineralogical component.

[14] To test if the loss of peak stress is due to initial compaction of the gouge leading to transient high pore pressures, we ran 'start-stop' experiments (Figure 3a) with a hold time of $\sim 10 \mathrm{~min}$. If initial compaction was responsible, then the peak friction should reappear after the hold time. The test was run with sandstone sliding blocks. We also investigated the possibility of thermal pressurization, using gabbro (relatively impermeable) and Berea sandstone (permeable, $\sim 10^{-15} \mathrm{~m}^{2}$ ) sliding blocks. If excess pore pressure was responsible, experiments with sandstone blocks would allow easier escape of pore fluid and hence might show higher strength. Although some frictional strengthening was observed (Figure $3 b$ ), the peak friction still did not re-emerge. We conclude from these investigations that the most likely cause of weakening and loss of fracture energy is due to very rapid thermal pressurization. Again, Ujiie and Tsutsumi [2010] reached the same conclusion with natural gouge from the Nankai trough. Similar results have been reached in theoretical studies [Segall and Rice, 2006], but this study provides some of the first experimental evidence to support this.

[15] In the experiments, the data sampling frequency per channel in the experiments was $200 \mathrm{~Hz}$ and, given the slip velocity, this equates to $\sim 6 \mathrm{~mm}$ of slip between each data point at the highest velocity, and proportionally smaller slip as the system is accelerating. Even if the peak friction is present in this missing part of the data record, i.e. in the displacement between times when data points are recorded, the equivalent fracture energy it represents is still very small.

[16] Figure 4a shows schematically how the stress varies during an earthquake rupture. Ahead of the rupture tip, the stress increases from background levels $\left(\tau_{\mathfrak{i}}\right)$ to a peak at the rupture tip $\left(\tau_{\mathrm{p}}\right)$ due to elastic loading. Behind the rupture tip, the stress decreases over some frictional breakdown distance (R) to the residual strength of the fault $\left(\tau_{\mathrm{r}}\right)$ during earthquake slip. Figure $4 \mathrm{~b}$ shows how the stress changes as a function of slip. The area under the curve (above $\tau_{\mathrm{r}}$ ) is known as the fracture energy (work of fracture) and its magnitude dictates the ease with which a rupture may propagate [Tinti et al., 2005; Cocco et al., 2006]. The implications of the results shown in Figure 2 are that earthquakes will not nucleate in low-normal stress clay-rich faults, but equally large ruptures may not be inhibited if they nucleate down dip and propagate upwards through the clay-rich upper region of the accretionary wedge.

[17] The conditions under which experiments were conducted are all low stress, and hence the results are most applicable to shallow zones such as the upper part of accretionary prisms. The experiments illustrate that earthquake propagation has little to do with whether it is velocity strengthening or weakening at slow slip velocity, as this only controls earthquake nucleation. The almost immediate weakening seen at high slip speeds, coupled with inertia, suggest that propagation is a separate process dictated by other parameters [Hirono et al., 2008]. Given this framework, future rupture modeling should be aimed at trying to understand other properties of tsunami earthquakes, such as the anomalous propagation speed.

[18] The results might also apply to higher stress conditions and hence other types of earthquake rupture at deeper crustal levels, as many mature faults contain clay-rich gouge in their core [see Faulkner et al., 2010, and references therein]. The slip heterogeneity in earthquakes [Wald and Heaton, 1994] might be explained by the presence of clay-rich portions of the fault that show little resistance to the propagation of large ruptures. In this case, clay-rich fault zones, which are commonly observed in nature, might not be aseismic as previously supposed, but may be capable of hosting large ruptures.

[19] Acknowledgments. DRF acknowledges a JSPS Short-Term Fellowship that facilitated this work and Hiroshima University for hosting the Fellowship.

[20] The Editor thanks Nicola De Paola for her assistance in evaluating this paper.

\section{References}

Bilek, S. L., and T. Lay (2002), Tsunami earthquakes possibly widespread manifestations of frictional conditional stability, Geophys. Res. Lett., 29(14), 1673, doi:10.1029/2002GL015215.

Bizzarri, A., and M. Cocco (2006), A thermal pressurization model for the spontaneous dynamic rupture propagation on a three-dimensional fault: 1. Methodological approach, J. Geophys. Res., 111, B05303, doi:10.1029/ 2005JB003862.

Boutareaud, S., D. G. Calugaru, R. Han, O. Fabbri, K. Mizoguchi, A. Tsutsumi, and T. Shimamoto (2008), Clay-clast aggregates: A new textural evidence for seismic fault sliding?, Geophys. Res. Lett., 35, L05302, doi:10.1029/ 2007GL032554.

Bowden, F. P., and D. Tabor (1950), The Friction and Lubrication of Solids, Oxford Univ. Press, Oxford, U. K.

Brantut, N., A. Schubnel, J. N. Rouzaud, F. Brunet, and T. Shimamoto (2008), High-velocity frictional properties of a clay-bearing fault gouge 
and implications for earthquake mechanics, J. Geophys. Res., 113, B10401, doi:10.1029/2007JB005551.

Cocco, M., P. Spudich, and E. Tinti (2006), On the mechanical work absorbed on faults during earthquake ruptures, Earthquakes Radiat. Energy Phys. Faulting, 170, 237-254.

Crawford, B. R., D. R. Faulkner, and E. H. Rutter (2008), Strength, porosity, and permeability development during hydrostatic and shear loading of synthetic quartz-clay fault gouge, J. Geophys. Res., 113, B03207, doi:10.1029/2006JB004634.

De Paola, N., T. Hirose, T. Mitchell, G. Di Toro, C. Viti, and T. Shimamoto (2011), Fault lubrication and earthquake propagation in thermally unstable rocks, Geology, 39(1), 35-38, doi:10.1130/G31398.1.

Di Toro, G., T. Hirose, S. Nielsen, G. Pennacchioni, and T. Shimamoto (2006), Natural and experimental evidence of melt lubrication of faults during earthquakes, Science, 311(5761), 647-649, doi:10.1126/science. 1121012 .

Di Toro, G., R. Han, T. Hirose, N. De Paola, S. Nielsen, K. Mizoguchi, F. Ferri, M. Cocco, and T. Shimamoto (2011), Fault lubrication during earthquakes, Nature, 471(7339), 494, doi:10.1038/nature09838.

Faulkner, D. R., C. A. L. Jackson, R. J. Lunn, R. W. Schlische, Z. K. Shipton, C. A. J. Wibberley, and M. O. Withjack (2010), A review of recent developments concerning the structure, mechanics and fluid flow properties of fault zones, J. Struct. Geol., 32, 1557-1575, doi:10.1016/j.jsg.2010.06.009.

Geist, E. L., and S. L. Bilek (2001), Effect of depth-dependent shear modulus on tsunami generation along subduction zones, Geophys. Res. Lett., 28(7), 1315-1318, doi:10.1029/2000GL012385.

Goldsby, D. L., and T. E. Tullis (2002), Low frictional strength of quartz rocks at subseismic slip rates, Geophys. Res. Lett., 29(17), 1844, doi:10.1029/2002GL015240.

Haberland, C., A. Rietbrock, D. Lange, K. Bataille, and T. Dahm (2009), Structure of the seismogenic zone of the southcentral Chilean margin revealed by local earthquake traveltime tomography, J. Geophys. Res., 114, B01317, doi:10.1029/2008JB005802.

Han, R., T. Shimamoto, T. Hirose, J. H. Ree, and J. Ando (2007), Ultralow friction of carbonate faults caused by thermal decomposition, Science, 316(5826), 878-881, doi:10.1126/science.1139763.

Hirono, T., H. Mukoyoshi, W. Tanikawa, H. Noda, K. Mizoguchi, and T. Shimamoto (2008), Frictional behavior and its seismological implications within thrusts in the shallow portion of an accretionary prism, Tectonophysics, 456(3-4), 163-170, doi:10.1016/j.tecto.2008.04.015.

Hirose, T., and M. Bystricky (2007), Extreme dynamic weakening of faults during dehydration by coseismic shear heating, Geophys. Res. Lett., 34, L14311, doi:10.1029/2007GL030049.

Hyndman, R. D., M. Yamano, and D. A. Oleskevich (1997), The seismogenic zone of subduction thrust faults, Isl. Arc, 6(3), 244-260, doi:10.1111/ j.1440-1738.1997.tb00175.x.

Ide, S., A. Baltay, and G. C. Beroza (2011), Shallow dynamic overshoot and energetic deep rupture in the $2011 \mathrm{Mw} 9.0$ Tohoku-Oki earthquake, Science, 332(6036), 1426-1429.

Ikari, M. J., D. M. Saffer, and C. Marone (2009), Frictional and hydrologic properties of clay-rich fault gouge, J. Geophys. Res., 114, B05409, doi:10.1029/2008JB006089.

Kanamori, H. (1972), Mechanism of tsunami earthquakes, Phys. Earth Planet. Inter., 6(5), 346-359, doi:10.1016/0031-9201(72)90058-1.

Logan, J. M., and K. A. Rauenzahn (1987), Frictional dependence of gouge mixtures of quartz and montmorillonite on velocity, composition and fabric, Tectonophysics, 144(1-3), 87-108, doi:10.1016/0040-1951(87) 90010-2.

Mitchell, T. M., and D. R. Faulkner (2008), Experimental measurements of permeability evolution during triaxial compression of initially intact crystalline rocks and implications for fluid flow in fault zones, J. Geophys. Res., 113, B11412, doi:10.1029/2008JB005588.

Mizoguchi, K., T. Hirose, T. Shimamoto, and E. Fukuyama (2007), Reconstruction of seismic faulting by high-velocity friction experiments: An example of the 1995 Kobe earthquake, Geophys. Res. Lett., 34, L01308, doi:10.1029/2006GL027931.

Moore, D. E., and D. A. Lockner (2004), Crystallographic controls on the frictional behavior of dry and water-saturated sheet structure minerals, J. Geophys. Res., 109, B03401, doi:10.1029/2003JB002582.

Noda, H. (2008), Frictional constitutive law at intermediate slip rates accounting for flash heating and thermally activated slip process, J. Geophys. Res., 113, B09302, doi:10.1029/2007JB005406.

Oleskevich, D. A., R. D. Hyndman, and K. Wang (1999), The updip and downdip limits to great subduction earthquakes: Thermal and structural models of Cascadia, south Alaska, SW Japan, and Chile, J. Geophys. Res., 104(B7), 14,965-14,991, doi:10.1029/1999JB900060.

Saffer, D. M., and C. Marone (2003), Comparison of smectite- and illiterich gouge frictional properties: application to the updip limit of the seismogenic zone along subduction megathrusts, Earth Planet. Sci. Lett., 215(1-2), 219-235, doi:10.1016/S0012-821X(03)00424-2.

Saffer, D. M., K. M. Frye, C. Marone, and K. Mair (2001), Laboratory results indicating complex and potentially unstable frictional behavior of smectite clay, Geophys. Res. Lett., 28(12), 2297-2300, doi:10.1029/ 2001 GL012869.

Segall, P., and J. R. Rice (2006), Does shear heating of pore fluid contribute to earthquake nucleation?, J. Geophys. Res., 111, B09316, doi:10.1029/ 2005JB004129.

Seno, T. (2002), Tsunami earthquakes as transient phenomena, Geophys. Res. Lett., 29(10), 1419, doi:10.1029/2002GL014868.

Shimamoto, T., and A. Tsutsumi (1994), A new rotary-shear high-speed frictional testing machine: its basic design and scope of research [in Japanese with English abstract], J. Tectonic Res. Group Jpn., 39, 65-78.

Smith, S. A. F., and D. R. Faulkner (2010), Laboratory measurements of the frictional properties of the Zuccale low-angle normal fault, Elba Island, Italy, J. Geophys. Res., 115, B02407, doi:10.1029/2008JB006274.

Tembe, S., D. A. Lockner, and T. F. Wong (2010), Effect of clay content and mineralogy on frictional sliding behavior of simulated gouges: Binary and ternary mixtures of quartz, illite, and montmorillonite J. Geophys. Res., 115, B03416, doi:10.1029/2009JB006383.

Tinti, E., P. Spudich, and M. Cocco (2005), Earthquake fracture energy inferred from kinematic rupture models on extended faults, J. Geophys Res., 110, B12303, doi:10.1029/2005JB003644.

Tobin, H. J., M. Kinoshita, J. Ashi, S. Lallemant, G. Kimura, E. J. Screaton, M. Kway Thu, H. Masago, D. Curewitz, and the expedition 314/315/316 scientists (2009), NanTroSEIZE stage 1 expeditions: Introduction and synthesis of key results, in NanTroSEIZE Project Stage 1, Proc. Integr. Ocean Drill. Program, 314-315, 1-20.

Ujiie, K., and A. Tsutsumi (2010), High-velocity frictional properties of clay-rich fault gouge in a megasplay fault zone, Nankai subduction zone, Geophys. Res. Lett., 37, L24310, doi:10.1029/2010GL046002.

Wald, D. J., and T. H. Heaton (1994), Spatial and temporal distribution of slip for the 1992 Landers, California, earthquake, Bull. Seismol. Soc. Am., 84(3), 668-691.

Wendt, J., D. D. Oglesby, and E. L. Geist (2009), Tsunamis and splay fault dynamics, Geophys. Res. Lett., 36, L15303, doi:10.1029/2009GL038295.

J. Behnsen and D. R. Faulkner, Rock Deformation Laboratory, Department of Earth and Ocean Sciences, University of Liverpool, 4 Brownlow St., Liverpool L69 3GP, UK. (faulkner@liverpool.ac.uk)

T. Hirose, Kochi Institute for Core Sample Research, JAMSTEC 200 Monobe-otsu, Nankoku, Kochi 783-8502, Japan.

T. M. Mitchell, Experimental Geophysics Laboratory, Institute for Geology, Mineralogy, and Geophysics, Ruhr-University Bochum, D-44780, Bochum, Germany.

T. Shimamoto, State Key Laboratory of Earthquake Dynamics, Institute of Geology, Chinese Earthquake Administration, Beijing, 100029, China. 